\title{
Effect of Hydroxide Ion Concentration on the Morphology of the Hydroxyapatite Nanorods Synthesized Using Electrophoretic Deposition
}

\author{
Khalil Abdelrazek Khalil, Abdulhakim A. Almajid, Mahmoud S. Soliman \\ Mechanical Engineering Department, College of Engineering, King Saud University, Riyadh, Saudi Arabia. \\ Email: kabdelmawgoud@ksu.edu.sa, khali1305@hotmail.com
}

Received December $16^{\text {th }}, 2010$; revised January $5^{\text {th }}, 2011$; accepted January $23^{\text {rd }}, 2011$.

\begin{abstract}
The effect of $\mathrm{OH}^{-}$concentration on the morphology of the hydroxyapatite (HA) nanorod synthesized using electrophoretic deposition (EPD) method has been investigated. The growth of HA nanorods was achieved on polished titanium substrates. The electrolyte used in this study was prepared by dissolving calcium acetate $\left(\mathrm{Ca}\left(\mathrm{CH}_{3} \mathrm{COO}\right)_{2} \mathrm{H}_{2} \mathrm{O}\right)$, and Ammonium dihydrogen phosphate $\left(\mathrm{NH}_{4} \mathrm{H}_{2} \mathrm{PO}_{4}\right)$ in distilled water without any surfactant, and was maintained at 80$130^{\circ} \mathrm{C}$. Two electrolytes with $\mathrm{OH}$ concentration of $10^{-4}$ and $10^{-10}$ were prepared. A highly homogeneous HA nanorods deposited on the titanium substrates were obtained after $1 \mathrm{~h}$ in the electrolytes with higher OH concentration of $10^{-4}$. On the other hand, a flower-shaped HA nanostructures composed of needle-like HA crystals were obtained in the electrolyte of lower $\mathrm{OH}$ concentration of $10^{-10}$. The deposits were identified as HA crystal rods grown along the c axis and perpendicular to the substrate. The HA deposits were characterized by scanning electron microscopy (SEM) while detailed structural characterization was done using a transmission electron microscope (TEM) equipped with selected area electron diffraction (SAED) patterns.
\end{abstract}

Keywords: Hydroxyapatite, Nanorods, Flower-Shaped, Electrophoretic Deposition, Synthesis

\section{Introduction}

Hydroxyapatite (HA: $\left.\mathrm{Ca}_{10}\left(\mathrm{PO}_{4}\right)_{6}(\mathrm{OH})_{2}\right)$ is a particularly attractive material for human tissue implantation. HA has similar chemical composition and crystal structure to apatite in the human skeletal system and is therefore suitable for bone substitution and reconstruction [1]. Hydroxyapatite can be synthesized via numerous production routes, using a range of different reactants, such as solidstate reactions [2], and wet chemical routes [3] based on precipitation at low temperatures. These conventional methods, however, usually prepare irregular forms of powders. A hydrothermal method, which has proved to be a convenient way to prepare materials including salts and metal oxides, has also been applied, but control of the morphology was poor [4]. Nevertheless, the size and morphology largely determine the behavior of a certain material, which is why a biomineralization process usually involves complicated mediation and the final products generally have a delicate microstructure [5]. Recently there have been some reports of attempts to as- semble the one-dimensional nanowires and nanorods directly into organized superstructures with the assistance of surfactants. Kim et al. [6] explored the organization of barium chromate nanorods at the water-air interface using the Langmuir-Blodgett (LB) technique. The inorganic nanorods were successfully assembled into isotropic, nematic, and smectic phases depending on the surface pressure. Kasuga and coworkers have developed a route to synthesize HA needle-like particles or fibers using crystalline $\beta-\mathrm{Ca}_{3}\left(\mathrm{PO}_{4}\right)_{2}$ fibers [7], but control of the morphology was poor. Therefore, synthesis of high crystalline HA nanorods is an urgent need of great significance, because bone itself is a composite consisting of HA nanorods embedded in the collagen matrix [8]. The application of surfactants as reverse micelles or microemulsions for the synthesis and self-assembly of nanoscale structures is one of the most widely adopted methods reported in the literature [9-18]. However, to the best of our knowledge no studies have been reported on the mechanism of fabrication of highly uniform HA nanorods without a surfactant. In this paper, we report 
the effect of $\mathrm{OH}^{-}$concentration on the morphology of the hydroxyapatite (HA) nanorod synthesized using electrophoretic deposition (EPD) method. A simple and controllable synthesis, without any surfactants, for highly uniform HA nanorods based on the $\mathrm{OH}^{-}$concentration have been introduced. Two electrolytes with different $\mathrm{OH}^{-}$concentration, based on different $\mathrm{pH}$ values have been used. The morphologies and structures of HA nanorods were characterized with scanning electron microscopy (SEM) and transmission electron microscopy (TEM).

\section{Materials and Methods}

Hydroxyapatite films were fabricated on polished titanium substrates using the electrophoretic deposition (EPD) method. A characteristic feature of this process is that colloidal particles suspended in a liquid medium migrate under the influence of an electric field (electrophoresis) and are deposited onto an electrode. A titanium plate $(10 \times$ $20 \times 1 \mathrm{~mm}$ ) was used as the cathode while a platinum plate $(20 \times 20 \times 0.5 \mathrm{~mm})$ was used as the anode. The electrolyte used in this study was prepared by dissolving calcium acetate $\left(\mathrm{Ca}\left(\mathrm{CH}_{3} \mathrm{COO}\right)_{2} \cdot \mathrm{H}_{2} \mathrm{O}\right)$, and Ammonium dihydrogen phosphate $\left(\mathrm{NH}_{4} \mathrm{H}_{2} \mathrm{PO}_{4}\right)$ in distilled water. The $\mathrm{Ca} / \mathrm{P}$ ratio was adjusted to be 1.67 , mimicking that of natural hydroxyapatite. The solution was buffered to a different $\mathrm{pH}$ value by ammonia. Calcium acetate and Ammonium dihydrogen phosphate solutions were initially prepared separately, then mixing of the two electrolytic solutions and the heating process were started simultaneously to avoid excessive bulk precipitation. Two electrolytes with $\mathrm{OH}^{-}$concentration of $10^{-4}$ and $10^{-10}$ were used, corresponding to the hydrogen ion $\left[\mathrm{H}^{+}\right]$concentration of $10^{-10}$ and $10^{-4}$, based on the following equation:

$$
\left[\mathrm{H}^{+}\right] \times\left[\mathrm{OH}^{-}\right]=10^{-14}=\mathrm{K}_{\mathrm{w}}
$$

The corresponding $\mathrm{pH}$ values of 10 and 4, respectively, were calculated as follows: Since the $\mathrm{pH}$ value is defined as:

$$
p H=-\log \left[H^{+}\right]
$$

The values of $\mathrm{pH}$ for the two solutions were 10 and 4 , respectively. The electrolyte was prepared in a Teflon capped air-tight glass bottle with the electrode assembly. The assembly (with electrolyte and electrodes) was heated to a temperature ranging from 80 to $130^{\circ} \mathrm{C}$ using a silicon oil bath. During heating and synthesis, the solution was agitated with magnetic stirring at a constant speed. Continuous stirring and aging are usually carried out after the reactants have been combined while the cal- cium is slowly incorporated into the apatitic structure. This process also helps the material to approach stoichiometric $\mathrm{Ca} / \mathrm{P}$ ratio. The current was maintained at 12.5 $\mathrm{mA} / \mathrm{cm}^{2}$ for 1 hour using a DC power supply. After electrodeposition, the titanium plates were rinsed with distilled water and dried in air. General morphology of the deposited HA nanorods was observed using scanning electron microscopy (SEM, JEOL model JSM-6610LV, Japan) and field-emission scanning electron microscope (FE-SEM, JEOL model, Japan), while detailed structural characterization was done with a transmission electron microscope (TEM, JEOL JEM-2010, Japan) equipped with selected area electron diffraction (SAED) patterns.

The SEM images were carried out by using a scanning electron microscope with an energy dispersive X-ray analyzer attached. Information about the phase and crystallinity was obtained by using Rigaku X-ray diffractometer (XRD, Rigaku, Japan) with $\mathrm{Cu} \mathrm{K \alpha}(\lambda=1.540 \AA)$ radiation over Bragg angle ranging from 10 to $80^{\circ}$. Spectroscopic analysis of the grown HAp microcrystals was carried out by FT-IR (AVATAR) using KBr pellet technique.

\section{Results and Discussion}

Hydroxyapatite nanorods deposited on the titanium substrates were obtained in the electrolytes with $\mathrm{OH}^{-}$concentration of $10^{-4}$ of a $\mathrm{pH}$ value of 10 , after 1 hour of electrophoretic processing at different electrolyte temperatures in the range of $80-130^{\circ} \mathrm{C}$, as shown in Figure 1. The SEM observations show that the HAp crystals deposited from the higher concentration electrolyte $\left(10^{-4}\right.$ $\mathrm{OH}^{-}$) are rod-like with a hexagonal cross section and diameters of about $50-200 \mathrm{~nm}$. The size of the deposited nanorods increased remarkably with the electrolyte temperature as shown in Figure 1.

Figure 2(a) shows FE-SEM image of HA nanorods. A schematic representation of a single HA nanorod showing the growth direction is shown in Figure 2(b). Selected area electron diffraction (SAED) pattern image obtained from the single HA nanorod projected along the $C$-axis is shown in Figure 2(c). The schematic representtation of a single HA nanorod suggested that, the HAp crystal with the longitude (vertical) direction of [002], and the six surface of the rod are (100). The size and morphology of the as-synthesized hydroxyapatite products were further examined by TEM and by selected area electron diffraction (SAED) patterns (shown in Figure 2(c)). The diameters of most nanorods are almost the same throughout their length, and all exhibited smooth and clean surfaces.

There are numerous ways to grow crystals. The choice of method depends greatly upon the physical and chemi- 


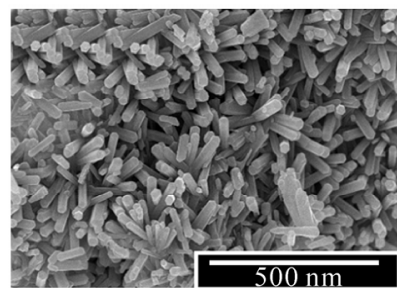

(a)

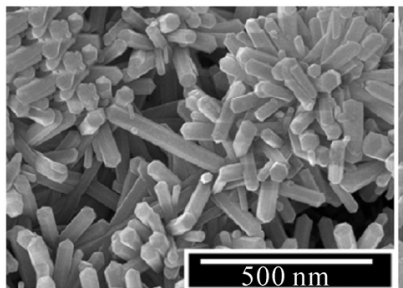

(c)

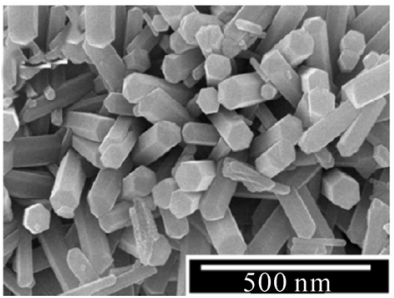

(e)

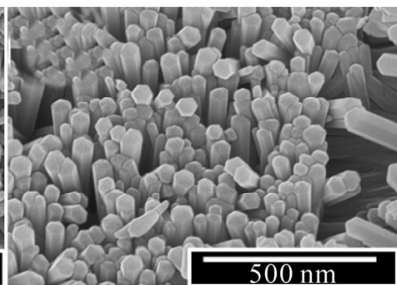

(b)

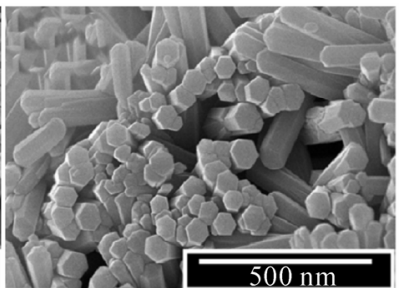

(d)

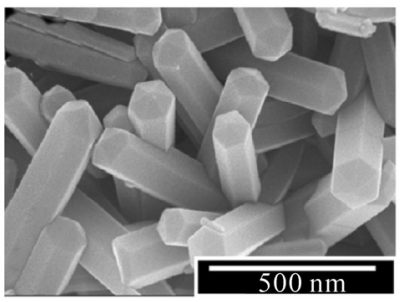

(f)
Figure 1. FE-SEM micrographs of the hydroxyapatite nanorods deposited on the titanium substrates at (a) $80^{\circ}$, (b) $90^{\circ}$, (c) $100^{\circ}$, (d) $110^{\circ}$, (e) $120^{\circ}$, and (f) $130^{\circ} \mathrm{C}$.

cal properties of the sample. For solution methods of crystallization, the solubility of the sample in various solvent systems must be explored. If heating methods are selected for growing crystals, the thermal stability and melting point of the sample should be determined. Few experiments were done to understand the growth process of hydroxyapatite nanorods in the presence of much higher $\mathrm{OH}^{-}$concentration and based on that experiments and results; we suggest here the formation mechanism for the obtained products are as follows: the hydroxyapatite is a polar hexagonal and highly anisotropic crystal and generally grows along the $c$-axis direction. Due to the anisotropic structure of hydroxyapatite (HAp), the nanoparticles of HAp start to combine into one unit and would be self-organized with each other and grow in their most favorable crystallographic direction i.e. $c$-axis [19]. In this accumulation process of the hydroxyapatite nanoparticles, the presence of $\mathrm{TiO}_{2}$ (in the surface of the titanium plate) is significant and it plays an important role for the formation of well faceted hydroxyapatite nanorods. Lee et al. [20] reported that the $\mathrm{TiO}_{2}$ is an effective nucleating agent for the calcium phosphates.

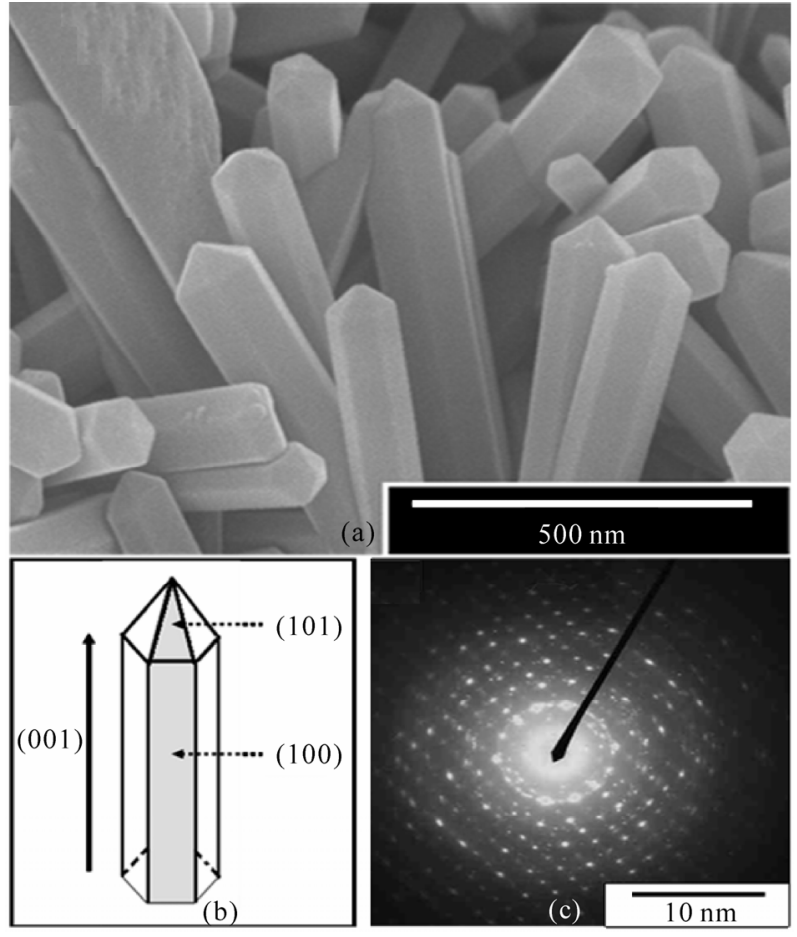

Figure 2. (a) FE-SEM image of HA nanorods and (b) A schematic representation of a single $\mathrm{HA}$ nanorod showing the growth direction, (c) Selected area electron diffraction (SAED) pattern image obtained from the single HA nanorod projected along the $C$-axis.

Hence, one can propose that the $\mathrm{TiO}_{2}$ in this synthesis acting as a catalyst to obtain a well crystallized $c$-axis oriented hydroxyapatite nanorods.

On the other hand, the possible nanorod nucleation and growth could be attributed to the relative specific surface energies associated with the different planes of HA crystal or nucleus. It is known that the crystal shape is determined by the relative specific surface energies associated with the facets of this particular crystal. Hence, some facets of the crystal have a preference to absorb $\mathrm{OH}^{-}$ions due to the different surface energies of the crystallite facets, prior to the growth units are incorporated into a crystal lattice, and this possibly restricts the movement of $\mathrm{Ca}^{2+}$ and $\mathrm{PO}_{4}{ }^{3-}$ in the formed nucleus in one particular direction. In this condition, $\mathrm{OH}^{-}$templates the nucleation process where free $\mathrm{Ca}^{2+}$ and $\mathrm{PO}_{4}{ }^{3-}$ react with $\mathrm{OH}^{-}$in uniaxial direction (planes with less $\mathrm{OH}^{-}$concentration), nucleating into HA nanorods. Thus, the shielding effect of the $\mathrm{OH}^{-}$ions on the interface will control the growth rate of the $\mathrm{OH}^{-}$absorbed facets [21]. Different facets of the crystals have different quantity of the $\mathrm{OH}^{-}$ions and its hindrance effect. If the larger quantity of the $\mathrm{OH}^{-}$will be available at the interface, the hindrance effect of the $\mathrm{OH}^{-}$ions will be stronger on the facets which will affect 
the growth rate in the various crystal facets. As the synthesis of the HAp nanorods was done at $\mathrm{pH} 10$ (higher $\mathrm{OH}^{-}$concentration), HAp nanoparticles may generate active site due to the strong absorption of the $\mathrm{OH}^{-}$ions. Moreover, the HAp crystals have faster growth rate along the $c$-axis, i.e. (001) direction as compared to other growth facets [22]. To know the role of higher $\mathrm{OH}^{-}$concentration and $\mathrm{TiO}_{2}$, various experiments are underway. Clearly more studies are required to obtain more conclusive evidences regarding the detailed growth process for the formation HAp nanorods in the presence of higher $\mathrm{OH}^{-}$concentration and $\mathrm{TiO}_{2}$.

These HAp nanoparticles with $\mathrm{OH}^{-}$ions in the presence of $\mathrm{TiO}_{2}$ may act as nuclei for the formation of HAp nanorods. So the subsequent attachment and merging of adjacent nanoparticles in accordance with the crystal lattice of the HAp give rise to the phase transformation from HAp nanoparticles to the HAp nanorods in the presence of higher $\mathrm{OH}^{-}$concentration and $\mathrm{TiO}_{2}$. Even one can predict that the $\mathrm{TiO}_{2}$ is acting as a catalyst for the transformation of HAp nanoparticles to the HAp nanorods but the actual role of higher $\mathrm{OH}^{-}$concentration and $\mathrm{TiO}_{2}$ are unclear. Remarkably, the size of the deposits increased with increasing the electrolyte temperature. The growth of HA nanorods with temperature can be described by "oriented attachment" mechanism reported for other ceramics like $\mathrm{TiO}_{2}[23]$.

In the present work, the electrolyte with much higher $\mathrm{OH}^{-}$concentration was employed and the rod-like HAp crystal has a much smaller diameter. The smaller size of the HAp crystal may be beneficial to the bioactivity of the coating. All the deposits were rod-like in shape, having a defined hexagonal crystal habit. Furthermore, it was found that the long rod-like crystals grew up perpendicular to the substrate. It is interesting to note that the synthesized HAp nanorods reported in this paper are also grown in $c$-axis at (001) direction as evident from the XRD data (Figure 3). Hydroxyapatite nanorods deposited on the titanium substrates were obtained in the electrolytes with $\mathrm{OH}^{-}$concentration of $10^{-10}$, based on the $\mathrm{pH}$ value of 10 , after $1 \mathrm{~h}$ of electrophoretic processing at different electrolyte temperatures as shown in Figure 1. The SEM observation shows that the HAp crystals prepared with higher concentration electrolyte $\left(1 \times 10^{-4} \mathrm{OH}^{-}\right)$are rodlike with a hexagonal cross section and diameters of about 50-200 nm.

In the electrolyte of lower $\mathrm{OH}^{-}$concentration of $10^{-10}$, a flower-shaped hydroxyapatite nanostructures composed of needle-like HA crystal was obtained. Figure 3 shows the SEM images of flower-shaped hydroxyapatite nanostructures composed of nanorods grown on Ti substrate by electrophoretic deposition at (a) $80^{\circ} \mathrm{C}$ and (b) $100^{\circ} \mathrm{C}$ (Fi-

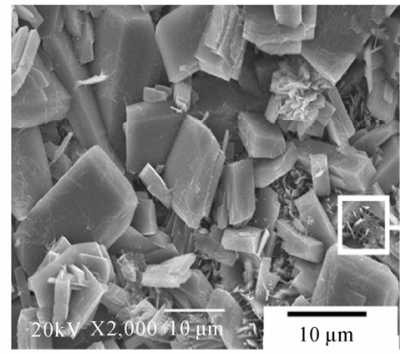

(a)

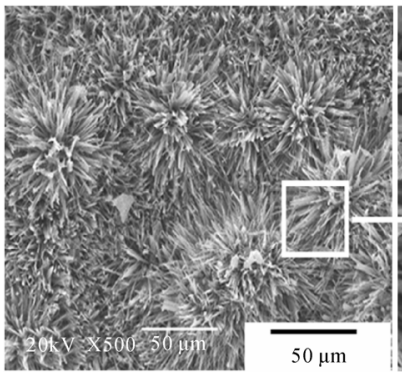

(b)

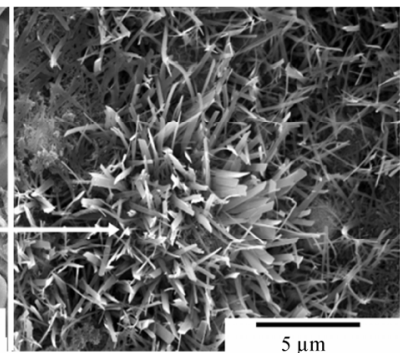

(a1)

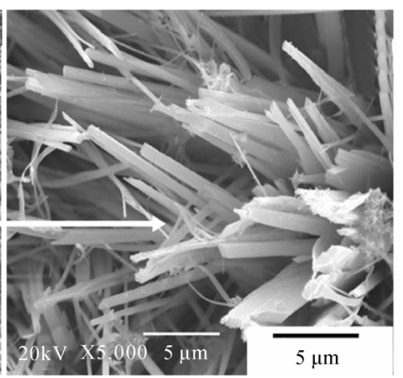

(b1)
Figure 3. SEM images of flower-shaped hydroxyapatite nanostructures composed of nanorods grown on Ti substrate by electrophoretic deposition at (a) $80^{\circ} \mathrm{C}$ and (b) $100^{\circ} \mathrm{C}$ (a1 and $b 1$ are high magnification images).

gures 3(a1) and 3(b1) are were taken at high magnification). From this Figure, we can see that at low temperature of $80^{\circ} \mathrm{C}$, a block-like morphology is found. As the process is maturated, a morphological change from "blocky" crystals to more needle-like crystals occurs, as shown in Figure 3(b). Figures 3(a1, b1) shows high magnification images of the as-grown materials. It is seen that hydroxyapatite precipitated uniformly on the surface to cover the surface entirely and consists of needle-like crystals radiating from a point in the form of a flower. Higher temperature produces a higher crystallinity product. The full width of one flower-like structure is about 50-60 $\mu \mathrm{m}$. In addition, the HA nanorods are randomly grown and they originate from the center of the flower. It seems that the central part of the flower-shaped structures provides a root for the growth of these HA nanorods. The precipitation behavior of hydroxyapatite on the titanium plate at low temperature resulted in block-like crystals and works as a root for the growth of HA nanorods at higher temperature.

Different morphology of crystal may imply the different mechanism of formation. Several authors have suggested that the electrolytes of lower $\mathrm{OH}^{-}$concentration usually accompanied with lower $\mathrm{pH}$ value and the octacalcium phosphate $\left(\mathrm{OCP}, \mathrm{Ca}_{8} \mathrm{H}_{2}\left(\mathrm{PO}_{4}\right)_{6} \cdot 5 \mathrm{H}_{2} \mathrm{O}\right)$ could be a precursor phase for HAp formation. Brown and Smith [24] suggested that OCP is the original precipitate on which 
biological apatite nucleates. In the present work, the electrolyte associated with ribbon-like HAp has a $\mathrm{pH}$ value of 4.0, more acidic than the electrolyte depositing rod-like $\mathrm{HAp}(\mathrm{pH}=10)$. Therefore, it might be possible that in the electrolyte of lower $\mathrm{OH}^{-}$concentration the OCP was formed during the deposition and took the morphology of needle-like.

The XRD patterns of the representative HAP samples are shown in Figure 4. This Figure shows that the two coatings exhibit typical apatite peaks at $2 \theta$ of $25.9^{\circ}$ and $31-33^{\circ}$, which correspond to the HAp (002) diffraction and a combination of the poorly resolved (211), (202) and (300) diffractions. The peaks from both coatings are in good agreement with the standard HAp patterns. All peaks could be indexed to a hexagonal HAp crystal. No characteristic peaks of impurities, such as calcium hydroxide and calcium phosphates, were observed, meaning that phase pure HAp was prepared under the present experimental conditions.

FT-IR studies also confirmed that the coatings consist of HAp crystals (Figure 5). The stretching mode of the $\mathrm{OH}^{-}$group appears at $3572 \mathrm{~cm}^{-1}$. The bands that correspond to the internal modes of $\mathrm{PO}_{4}^{3-}$ group occur at $\mathrm{v} 1$ $\left(600,570 \mathrm{~cm}^{-1}\right)$ and $\mathrm{v} 2\left(1085,1033 \mathrm{~cm}^{-1}\right)$. The $\mathrm{OH}$ stretching band at $3572 \mathrm{~cm}^{-1}$ is considered as the indication of HAp structure [25].

\section{Conclusions}

A simple and controllable synthesis, without surfactants, of hexagonal hydroxyapatite nanorods by using electrophoretic deposition has been reported. The hydroxyapatite nanorods were formed on a titanium electrode at temperatures ranging from 80 to $130^{\circ} \mathrm{C}$.

1) The morphology of hydroxyapatite crystal can be effectively controlled by the concentration of $\mathrm{OH}^{-}$in the electrolytes prepared for the deposition.

2) When $\mathrm{OH}^{-}$concentration was $10^{-4}$, a highly uniform nanorod HAp crystal can be deposited on the titanium surface. The size of the deposited nanorods increased remarkably with increasing electrolyte temperature, While, in the electrolyte with lower $\mathrm{OH}^{-}$concentration of $10^{-10}$, a needle-like flower-shaped HA can be prepared.

3) In the electrolyte with lower $\mathrm{OH}^{-}$concentration of $10^{-10}$, a block-like HA crystals were obtained at electrolyte temperatures of $80^{\circ} \mathrm{C}$, while a gradual change to needle-like flower-shaped HA occurred at $100^{\circ} \mathrm{C}$ electrolyte temperature.

4) The high resolution FE-SEM images and selected area electron diffraction patterns showed that the nanostructures obtained are single crystalline with hexagonal structure, grown along the direction of the $c$-axis.

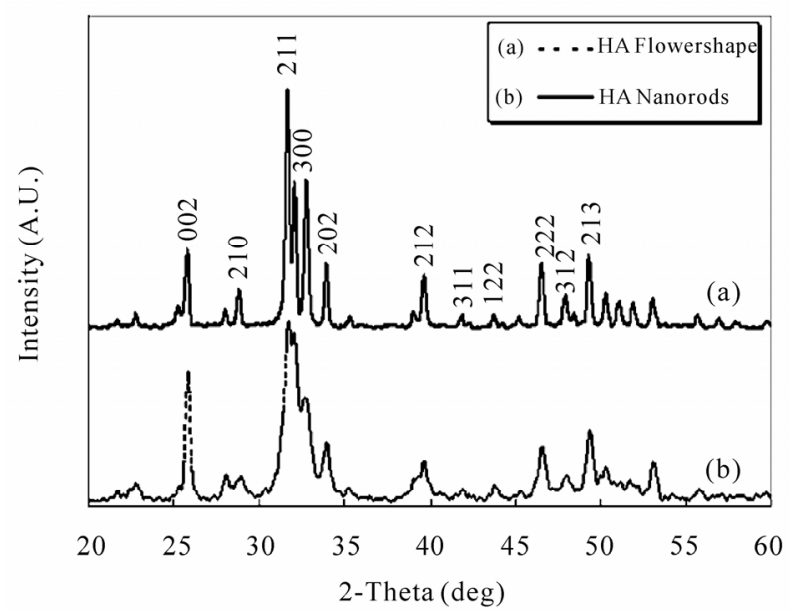

Figure 4. The XRD patterns of the representative HAp nanorods. (a) HA Flowershape; (b) HA Nanorods.

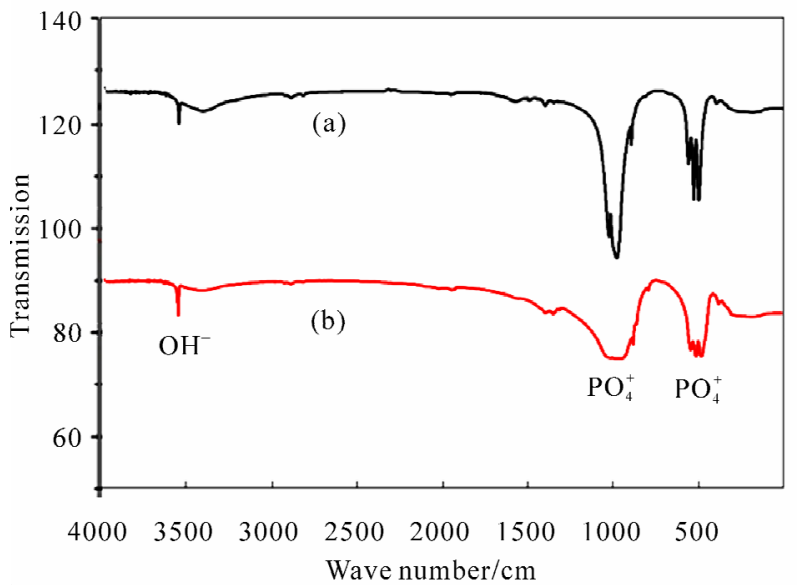

Figure 5. The FTIR spectra of HA synthesized under different $\mathrm{OH}^{-}$concentration.

\section{Acknowledgements}

This work was supported by Research Center, College of Engineering, King Saud University, Kingdom of Saudi Arabia under Project No. 23/430.

\section{REFERENCES}

[1] Y. M. Kong, S. Kim and H. E. Kim, "Reinforcement of Hydroxyapatite Bioceramic by Addition of $\mathrm{ZrO}_{2}$ Coated with $\mathrm{Al}_{2} \mathrm{O}_{3}$," Journal of the American Ceramic Society, Vol. 82, No. 11, 1999, pp. 2963-2968. doi:10.1111/j.1151-2916.1999.tb02189.x

[2] W. Suchanek and M. Yoshimura, "Processing and Properties of Hydroxyapatite-Based Biomaterials for Use as Hard Tissue Replacement Implants," Journal of Materials Research, Vol. 13, No. 1, 1998, pp. 94-117. doi:10.1557/JMR.1998.0015

[3] M. H. Fathi and A. Hanifi, "Evaluation and Characteriza- 
tion of Nanostructure Hydroxyapatite Powder Prepared by Simple Sol-Gel Method," Materials Letters, Vol. 61, No. 18,2007 , pp. 3978-3983.

doi:10.1016/i.matlet.2007.01.028

[4] M. Yoshimura, H. Suda, K. Okamoto and K. Ioku, "Hydrothermal Synthesis of Biocompatible Whiskers," Journal of Materials Science, Vol. 29, No. 1994, pp. 3399-3402.

doi:10.1007/BF00352039

[5] S. Mann and G. A. Ozin, "Synthesis of Inorganic Materials with Complex Form," Nature, Vol. 382, No. 6589, 1996, pp. 313-318.

doi: $10.1038 / 382313 \mathrm{a} 0$

[6] F. Kim, S. Kwan, J. Akana and P. Yang, "LangmuirBlodgett, Nanorod Assembly," Journal of the American Ceramic Society, Vol. 123, No. 18, 2001, pp. 4360-4361.

[7] Y. Ota, T. Iwashit, T. Kasuga and Y. Abe, "Novel Preparation Method of Hydroxyapatite Fibers," Journal of the American Ceramic Society, Vol. 81, No. 6, 1998, pp. 1665-1668. doi:10.1111/j.1151-2916.1998.tb02529.x

[8] A. Tiselius, S. Hjertén and O. Levin, "Protein Chromatography on Calcium Phosphate Columns," Archives of Biochemistry and Biophysics, Vol. 65, No. 1, 1956, pp. 132-155.

doi:10.1016/0003-9861(56)90183-7

[9] O. Fowler, "Infrared Studies of Apatites. II. Preparation of Normal and Isotopically Substituted Calcium, Strontium, and Barium Hydroxyapatites and Spectra-StructureComposition Correlations," Inorganic Chemistry, Vol. 13, No. 1,1974 , pp. 207-214 doi:10.1021/ic50131a040

[10] A. Bigi, E. Boanini and K. Rubini, "Hydroxyapatite Gels and Nanocrystals Prepared through a Sol-Gel Process," Journal of Solid State Chemistry, Vol. 177, No. 9, 2004, pp. 3092-3098. doi:10.1016/j.jssc.2004.05.018

[11] M. Li, H. Schnablegger and S. Mann, "Coupled Synthesis and Self-Assembly of Nanoparticles to Give Structures with Controlled Organization," Nature, Vol. 402, No. 6760, 1999, pp. 393-395. doi: $10.1038 / 46509$

[12] D. Walsh, J. D. Hopwood and S. Mann, "Construction of Reticulated Calcium Phosphate Frameworks in Bicontinuous Reverse Microemulsions," Science, Vol. 264, No. 5165,1994 , pp. $1576-1578$. doi:10.1126/science.264.5165.1576

[13] Y. Liu, W. Wang, Y. Zhan, C. Zheng and G. Wang, "A Simple Route to Hydroxyapatite Nanofibers," Materials Letters, Vol. 56, No. 4, 2002, pp. 496-501. doi:10.1016/S0167-577X(02)00539-6

[14] S. Bose and S. K. Saha, "Synthesis and Characterization of Hydroxyapatite Nanopowders by Emulsion Technique," Chemistry of Materials, Vol. 15, No. 23, 2003, pp. 44644469.

\section{doi: $10.1021 / \mathrm{cm} 0303437$}

[15] J. D. Hopwood and S. Mann, "Synthesis of Barium Sulfate Nanoparticles and Nanofilaments in Reverse Micelles and Microemulsions," Chemistry of Materials, Vol. 9, No. 8, 1997, pp. 1819-1828. doi:10.1021/cm970113q

[16] X. Peng, L. Manna, W. Yang, J. Wickham, E. Scher, A. Kadavanich and A. P. Alivisatos, "Shape Control of CdSe Nanocrystals," Nature, Vol. 404, No. 6773, 2000, pp. 59-61. doi:10.1038/35003535

[17] N. R. Jana, L. A. Gearheart, S. O. Obare, C. J. Johnson, K. J. Edler, S. Mann and C. J. Murphy, "Liquid Crystalline Assemblies of Ordered Gold Nanorods," Journal of Materials Chemistry, Vol. 12, No. 10, 2002, pp. 2909-2912. doi: $10.1039 / \mathrm{b} 205225 \mathrm{c}$

[18] Z. Liu, Z. Hu, J. Liang, S. Li, Y. Yang, S. Peng and Y. Qian, "Size-Controlled Synthesis and Growth Mechanism of Monodisperse Tellurium Nanorods by a Surfactant-Assisted Method," Langmuir, Vol. 20, No. 1, 2004, pp. 214-218. doi:10.1021/la035160d

[19] M. I. Kay, R. A. Young and A. S. Posner, "Crystal Structure of Hydroxyapatite," Nature, Vol. 204, No. 4963, 1964, pp. $1050-1052$. doi: $10.1038 / 2041050 \mathrm{a} 0$

[20] J.-S. Lee and C.-K. Hsu, "The Devitrification Behavior of Calcium Phosphate Glass with $\mathrm{TiO}_{2}$ Addition," Thermochimica Acta, Vol. 333, No. 2, 1999, pp. 115-119. doi:10.1016/S0040-6031(99)00095-7

[21] W. J. Li, E. W. Shi, W. Z. Zhong and Z. W. Yin, "Growth Mechanism and Growth Habit of Oxide Crystals," Journal of Crystal Growth, Vol. 203, No. 1-2, 1999, pp. 186-196. doi:10.1016/S0022-0248(99)00076-7

[22] G. C. Koumoulidis, T. C. Vaimakis and A. T. Sdoikos, "Preparation of Hydroxyapatite Lathlike Particles Using High-Speed Dispersing Equipment," Journal of the American Ceramic Society, Vol. 84, No. 6, 2001, pp. 1203-1208. doi:10.1111/j.1151-2916.2001.tb00817.x

[23] J. N. Nian and H. Teng, "Hydrothermal Synthesis of Single-Crystalline Anatase $\mathrm{TiO}_{2}$ Nanorods with Nanotubes as the Precursor," The Journal of Physical Chemistry B, Vol. 110, No. 9, 2006, pp. 4193-4198. doi:10.1021/jp0567321

[24] W. E. Brown and J. P. Smith, "Octacalcium Phosphate and Hydroxyapatite: Crystallographic and Chemical Relations between Octacalcium Phosphate and Hydroxyapatite," $\mathrm{Na}$ ture, Vol. 196, 1962, pp. 1050-1055. doi:10.1038/1961050a 0

[25] M. Ashok, N. M. Sundaram and S. N. Kalkura., "Crystallization of Hydroxyapatite at Physiological Temperature," Materials Letters, Vol. 57, No. 13-14, 2003, pp. 2066-2070. doi:10.1016/S0167-577X(02)01140-0 